\title{
Effects of the Time Perspectives on Substance Abuse
}

\author{
Anuj Suneja ${ }^{1}$, Joel V Joseph ${ }^{2}$, Pragyendu ${ }^{3}$
}

\section{ABSTRACT}

Substance abuse is in the process of becoming a gigantic disaster for the whole so called "fancy world” and so are the rates of abuse mounting in India. It has become aperil for human existence. Print media and electronic media frequently report substance abuse and their consequences. It has been reported that Drug abuse has become a grave problem and also point out exponential growth of drug abuse amongst the youth of our country. Purposely participants $(\mathrm{N}=68)$ were drawn. Primarily administered ZTPI (Zimbardo Time Perspective Inventory) on some participants who involve in drug abuse and some who don't, of which only 49 participants were selected who had a present or future time perspective orientation. The second thing this study tries to analyse is whether time perspectives and time zones which general people follow play a role in substance abuse. Results reveal that people identified as having a more present time perspective (PTP) are more likely to be report using drugs whereas people identified as having a more orientation towards the future time perspective (FTP) was negatively related to the reported substance abuse.

Keywords: Substance Abuse, the Time Zones, Present time perspective, Future time perspective.

Embarking into university life is a passage into adulthood. It is a marked shift from strict school life and also from strict parenting styles in a country like India. Here new opportunities and experiences come in and it is this point of time which calls for close observation of the changes which occur in the technical wiring in the brain and minds of so called juveniles. From everyday reports in the print and social media to the direct dialogue of this problem in Prime Minister Narendra Modi's speech in "MANN KI BAAT"; we come to know about the abstemiousness of this problem and also up to what extent the roots of this issue have reached in our society.

\section{Substance Abuse}

Drug abuse or more appropriately substance abuse has become an acute problem in the Indian country and especially in the northern and north-eastern part of the subcontinent; the statistics show that there has been a recent surge in the particular epidemic of substance abuse which has taken the problem to new higher and startling magnitudes in the country. "Drug use, misuse or

\footnotetext{
${ }^{1}$ Student, Dept. of Applied Psychology, Sri Aurobindo College (Evening), University of Delhi.

${ }^{2}$ Student, Dept. of Applied Psychology, Sri Aurobindo College (Evening),University of Delhi.

${ }^{3}$ Asst. Professor, Dept. of Applied Psychology, Sri Aurobindo College (Evening),University of Delhi. *Corresponding Author

(C) 2015 I A Suneja, J Joseph, Pragyendu; licensee IJIP. This is an Open Access Research distributed under the terms of the Creative Commons Attribution License (http://creativecommons.org/licenses/by/2.0), which permits unrestricted use, distribution, and reproduction in any Medium, provided the original work is properly cited.
} 


\section{Effects of the Time Perspectives on Substance Abuse}

abuse is also primarily due to the nature of the drug abused, the disposition of the individual and the addict's immediate environment”.

Fetchener has argued that Substance abuse, also known as drug abuse and substance use disorder, is a patterned use of a drug in which the user ingests the drug in amounts or with approaches which are harmful to themselves or others, and is a form of substance-related ailments.

According to the World Health Organization (WHO) substance abuse is persistent or sporadic drug use inconsistent with or unrelated to acceptable medical practice.

\section{History of drugs}

In India, marijuana and many other drugs have been used for millenniums. Alcoholic beverages have a unique but similar history of their preparation, fermentation, and production since the 4000 BC. Both beer and rum were produced at the same time in what are now Iraq and Iran. Marijuana is thought to be originated in china about 4000 years age and after that India gave a follow up for its origin and development. Prior to the psychoactive use of marijuana (hemp) it was used as a fibre, and traces of its use as cloth date back more than 10,000 years in China. Since the First World War marijuana, hash and other drugs are being misused in Indian subcontinent and Asian continent. Hash and marijuana are just the representatives of the groups there are many other drugs like hemp, heroin, coke, fluid etc. which have been abused since the $4^{\text {th }}$ century and are still in fashion.

A drug is a chemical substance that arouses some changes in the body According to World Health Organization (1969) a drug is any substance that when taken into the organism may modify one or more functions. According to a leading journal named after FORCON Forensic consulting "the ancient Greeks believed drugs to be both poison and medicine”. In modern psychology, a drug is whatever is consumed to treat any therapeutic or psychosomatic condition. "Often what determines whether a substance is a drug is its manner of use”. For example, alcohol is a beverage but it may be considered a drug if it is used for relaxation or to remove inhibitions. Similarly, it is used as a drug if it is taken to stimulate appetite.

\section{The Time Perspective}

Professor emeritus of psychology at Stanford University Philip Zimbardo devised the notion of time perspective. After a decade of intense research, he resolved that our attitude toward time is just as defining as key personality traits such as optimism or sociability. He believes that time perspective influences many of our judgements, decisions, and actions. Zimbardo recommended that a more future-based time perspective could help students study and progress to higher education. According to Zimbardo and Boyd in their scholarly article in 1999 "Time perspective is a fundamental dimension in the construction of psychology that emerges from the cognitive processes that partitions the human experience into past, present and the future”. 


\section{Effects of the Time Perspectives on Substance Abuse}

In 30 years of research, investigators have discovered that there 6 time zones in which general people live of which 2 focus on the past 2 on the present and 2 on the future. People who focus on the past either they remember all the happy things or the golden times like the successes, happy birthdays, nostalgia etc. these are the people who are called past positive and there is another category of people who focus on all failures and regrets of their past life they are called past negative. The other categories are the present oriented and the future oriented, the present oriented focus on the present the main ones being the hedonistic i.e. the people who live for pleasure and avoid pain and these are the ones who seek knowledge and sensation. The other people who are present oriented say that it doesn't pay to plan, they believe that their life is fated (by religion, poverty, fated by the conditions which they are living under). Most of us are here because we are future oriented people i.e. we have been classically conditioned to work rather than play and also trained to avoid temptation. But still there is another way to be future oriented like depending upon our religion "life begins after the death of a mortal body". To be future oriented you need trust and other positive traits, like in the Sicilian dialect there is no future tense and hence no future orientation the live in the present. According to Zimbardo and Boyd in 1999 "the nearer you live to the equator the more likely are you to be more present oriented". According to Zimbardo's former studies it has been found that Drug abuse has a positive and significant relationship with Present perspectives and time zones i.e. Present Hedonistic and Present Fatalistic, it has also been found that the more a person is future oriented the less is the likelihood of his or her involvement in drugs.

Zimbardo acknowledged five key tactics to time perspective. They are:

1. The 'past-negative' type. This person focuses on negative personal experiences that still have the power to upset them, which can lead to feelings of bitterness and regret.

2. The 'past-positive' type. These people have a nostalgic view of the past, and stay in very close contact with their family. They tend to have happy relationships, but their downside is a cautious, "better safe than sorry" approach is the one which may hold them back.

3. The 'present-hedonistic' type. They are dominated by pleasure-seeking compulsions; they are reluctant to postpone feeling good for the sake of greater gain later. These are popular but tend to have a less healthy lifestyle and take more risks.

4. The 'present-fatalistic' type. They don't enjoy the present but feel trapped in it, unable to change the inevitability of the future. This sense of powerlessness leads to anxiety, depression and risk-taking.

5. The 'future-focused' type. People who are highly ambitious, focused on goals, and big on making 'to do' lists fit in this category. Their investment in the future can come at the cost of close relationships and recreation time.

All five types come into play in our lives at some point, but there probably will be one or two directions in which you are more focused. Identify these and you can start developing a more flexible, healthier approach. Our time perspective - whether we tend to get stuck in the past, live only for the moment, or are enslaved by our ambitions for the future - can predict everything from educational and career success to general health and happiness. 


\section{OBJECTIVES}

$>$ To study the effect of time perspective on the severity of drug abuse.

$>$ To confirm the internal correlation of the time perspectives used in theZimbardo Time Perspective Inventory (ZPTI).

\section{METHOD}

\section{Participants:}

Data was collected from 68 college going students of various colleges of Delhi using simple stratified sampling. Only those participants were included in the sample who had an orientation towards present and future time perspectives as classified by Philip G Zimbardo. The sample included was 49 participants (males $=25$, females $=24$; mean age $=19.40, \mathrm{SD}=1.18$ ).Participants were assured of confidentiality and anonymity and upon their agreement to participate, data was collected from them through a set of questionnaires.

\section{Measures:}

DRUG USE QUESTIONNAIRE (DAST-20): The Drug Abuse Screening Test (DAST) was developed in 1982 by Skinner H.A. and Ross H.E. is still an excellent screening tool. The assessment of drug use and related problems is important for both prevention and clinical care. Reliable and valid measures are excellent tools for identifying problems in health care and community settings, for health education, and for evaluating the effectiveness of treatment. It is a 20 item yes /no questionnaire which has no dimensions and has binary scoring.

ZIMBARDO TIME PERSPECTIVE INVENTORY (ZTPI): The Zimbardo time perspective inventory was developed by Philip G Zimbardo in 1999 when he gave the concept of time perspective in his celebrated study with John Boyd. The 5 factors of ZPTI were established through confirmatory and exploratory factor analyses and demonstrate high internal consistency and test retest reliability. It is a 56 item questionnaire which tries to assess the time perspective a person follows and time zone a person lives in.

\section{RESULTS}

Table 1: Interrelationship between drug abuse and the present hedonistic perspective, present fatalists perspective and future perspective orientation.

\begin{tabular}{|l|l|l|l|l|}
\hline VARIABLE & \multicolumn{1}{|c|}{ DAST } & PRESENT HED & PRESENT FAT & FUTURE \\
\hline & & & & \\
\hline DRUG ABUSE & 1 & $.840^{* *}$ & $.760^{* *}$ & $-.692^{* *}$ \\
\hline & & & & \\
\hline PRESENT HED & & 1 & $.613^{*}$ & $-.630^{*}$ \\
\hline & & & & $-.726^{*}$ \\
\hline PRESENT FAT & & & 1 & 01 \\
\hline & & & & \\
\hline FUTURE & & & & \\
\hline
\end{tabular}

${ }^{*} p<0.05 ; * * p<0.01$ 


\section{Effects of the Time Perspectives on Substance Abuse}

A perusal of Table1 shows a significant positive correlation between Drug Abuse and the present hedonistic perspective, Drug Abuse and present fatalistic perspective. Drug abuse is seen to have a significant negative correlation with the future time perspective scores. A significant positive correlation is seen between both the present oriented time perspectives. Also we can easily observe that the present time perspectives are significantly and negatively related to the future time perspective.

Table 2: Result of regression analysis treating Substance abuse as criterion variable and the dimensions of time perspective as predictors:

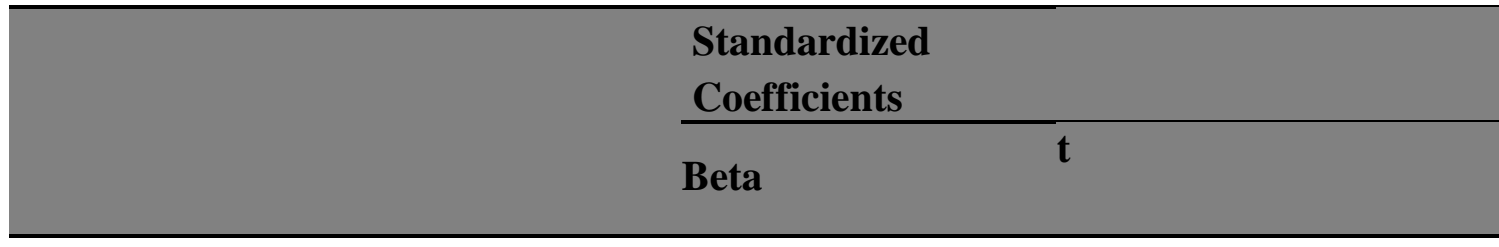

(Constant)

1.72

Present Hedonistic

.50

$4.37 * *$

Present Fatalistic

.10

.69

Future

$-.46$

$-5.28 * *$

$N=49$

$R=0.920, R^{2}=0.847, F=83.123$, Sig. $<0.001$

A review of table 2 shows that the multiple $\mathrm{R}$ is 0.920 which shows a high and significant correlation among all the variables. The $\mathrm{R}^{2}$ is 0.847 implying that $84.7 \%$ of the variance in severity of Drug Abuse is contributed by all the predictors used in the study. F value of 83.123 is seen to be significant at $<0.001$ which implies a good model fit. In other to examine the individual influences of the predictors of Drug abuse standardized beta coefficients were calculated. It is observed that the time perspective of Present hedonistic emerged as a significant predictor of Drug abuse with a Beta coefficient of 0.50. It was also noted that the Present fatalistic is also a predictor of drug abuse but it is not a very significant predictor. However, the time perspective of future is comprehended to predict Drug abuse in the negative direction but in a very significant and diplomatic way with a beta coefficient of -0.46 .

\section{DISCUSSION:}

The purpose of the study was to study the association of drug abuse with Time Perspective (as stated by Phillip G Zimbardo). 49 students of Delhi and NCR were contacted through stratified sampling and were assessed in the above mentioned Dimensions of Time Perspective and 


\section{Effects of the Time Perspectives on Substance Abuse}

severity of Substance Abuse) through questionnaires. The results and conclusion drawn from this study may be used for further research and the results of this study provide the further researchers with Indian Data which is not available today and where it is available it is very weak or poor. Results were analysed through Pearson's coefficient of correlation and Regression analysis. The results of the study are deliberated as following according to the results tables:

The first table shows the correlation of different variables used in the study i.e. the different dimensions of the time perspective and Substance abuse as a whole. The results show that there is a significant and positive correlation between the present hedonistic and present fatalistic with substance abuse $(\mathrm{r}=.840 ; p<.01)$ and $(\mathrm{r}=.760 ; p<.01)$, whereas the correlation between future perspective orientation and drug abuse is noted to be negative and highly significant $(\mathrm{r}=-.692$; $p<.01$ ), which shows that more a person is present oriented the more is his likelihood of being a severe drug abuser this further means that a present oriented person is more vulnerable to drug abuse than a future or past oriented person, this confirms with the results of the study of Zimbardo and Boyd in 1999on time perspective and drug abusers.

The table also shows that there is a strong internal correlation between the dimensions of the time perspective, where a significant and positive correlation is found between both the present time perspectives a contrasting strong and negative correlation is found between future and present time perspectives which once again confirms the results of Zimbardo's 1999 study and also demonstrates the high internal correlation of the dimensions of the questionnaire which further depicts the reliability and validity of the measure used.

The second table shows the results for regression analysis of the study which is depicted by the values of $R$ and $R^{2}$ (R squared) the value of $R$ is found to be 0.920 which shows a high and significant correlation among all the variables and $\mathrm{R}^{2}$ is 0.847 implying that $84.7 \%$ of the variance in severity of Drug Abuse is contributed by all the predictors used in the study. This shows that predictors i.e. the different perspectives of time affect the severity of drug abuse very considerably. The F value of 83.123 is seen to be significant at 0.001 which implies a good model fit. It is observed that the time perspective of Present hedonistic emerged as a significant predictor of Drug abuse with a Beta coefficient of 0.50. It was also noted that the Present fatalistic is also a predictor of drug abuse but it is not a very significant predictor. However, the time perspective of future is comprehended to predict Drug abuse in the negative direction but in a very significant and diplomatic way with a beta coefficient of -0.46 . By these finding we can say that future perspective affects the drug variable significantly but in a deleterious way whereas the present perspective affects the same in a positive and significant way. These results also confirm the results of the Zimbardonian perspective study.

\section{CONCLUSION}

The study has shown positive and strong or significant relationship between Substance Abuse and Present hedonistic and fatalistic time perspectives whereas a negative and significant correlation is observed between substance abuse and Future time orientation, which clearly 


\section{Effects of the Time Perspectives on Substance Abuse}

points out that a present time oriented person is more likely to involve in drug abuse rather than a person who is more oriented towards future i.e. a person who has some ambitions and goals is more likely to avoid drugs and alcohol. It was also noted that there is a high correlation between dimensions of time perspectives which confirms the Internal consistency of the Zimbardo Time perspective inventory i.e. a person can be only one perspective oriented throughout his life and the change of orientation can take place only when a person goes through a severe nervous or psychological breakdown. In the Indian context mostly present oriented people are found because India is located near the equator and this leads to some deviations from the ideal Zimbardonian study.

\section{REFERENCES}

Ahmad N., Bano R., Agarwal V, Kalakoti P. (2009), Substance Abuse In India .Pravara Medical Review; volume 1(4)

Blazina, Chris; Watkins Jr., C. Edward D. (1996) Masculine gender role conflict: Effects on college men's psychological well-being, chemical substance usage, and attitudes towards help-seeking. Journal of Counselling Psychology, Vol 43(4), 461-465

Degenhardt, Louisa; Hall, Wayne; Lynskey, Michael(2001)Alcohol, cannabis and tobacco use among Australians: a comparison of their associations with other drug use and use disorders, affective and anxiety disorders, and psychosimCarfax Publishing, part of the Taylor \& Francis Group; Addiction, Volume 96, Number 11, pp. 1603-1614(12)

NIAAA. A Call to Action: Changing the Culture of Drinking at U.S. Colleges. Bethesda, MD: NIAAA;

Wills, Thomas Ashby; Sandy, James M.; Yaeger, Alison M, Time perspective and early- onset substance use: A model based on stress-coping theory, Psychology of Addictive Behaviors, Vol 15(2), Jun 2001, 118-125

WHO.Techn. Res. Ser. No.886: 1999. p. 48.

Zimbardo P. and Boyd J. Putting Time in Perspective: A Valid, Reliable Individual-Difference Metric. The Journal of Personality and Social Psychology, Vol. 77, 1999, pp. 1271-88. 